\title{
Genomic analysis of diet composition finds novel loci and associations with health and lifestyle
}

\author{
S. Fleur W. Meddens ${ }^{1,2} \cdot$ Ronald de Vlaming $^{1} \cdot$ Peter Bowers $^{3} \cdot$ Casper A. P. Burik $^{1}$ Richard Karlsson Linnér (I) $^{1}$. \\ Chanwook Lee $^{3}$ - Aysu Okbay $\mathbb{D}^{1}$ - Patrick Turley ${ }^{4,5,6} \cdot{\text { Cornelius A. Rietveld } \mathbb{D}^{2,7,8} \text {. Mark Alan Fontana }}^{9,10}$. \\ Mohsen Ghanbari $\mathbb{D}^{7,11} \cdot$ Fumiaki Imamura $\mathbb{1}^{12} \cdot$ George McMahon ${ }^{13} \cdot$ Peter J. van der Most $\mathbb{D}^{14}$. \\ Trudy Voortman $\mathbb{D}^{7} \cdot$ Kaitlin H. Wade $\mathbb{D}^{13} \cdot$ Emma L. Anderson ${ }^{13} \cdot$ Kim V. E. Braun $\mathbb{D}^{7} \cdot$ Pauline M. Emmett ${ }^{15}$. \\ Tonũ Esko ${ }^{16}$ • Juan R. Gonzalez $\mathbb{1}^{17,18,19}$ • Jessica C. Kiefte-de Jong $\mathbb{D}^{7,20} \cdot$ Claudia Langenberg $\mathbb{D}^{12}$. \\ Jian'an Luan $\mathbb{1}^{12} \cdot$ Taulant Muka ${ }^{7}$. Susan Ring $\mathbb{1}^{13} \cdot$ Fernando Rivadeneira $\mathbb{1}^{21} \cdot$ Harold Snieder $\mathbb{C}^{14}$. \\ Frank J. A. van Rooij $\mathbb{D}^{7}$ - Bruce H. R. Wolffenbuttel $\left.\right|^{22} \cdot 23$ andMe Research Team - EPIC- InterAct Consortium • \\ Lifelines Cohort Study $\cdot$ George Davey Smith $\mathbb{1}^{13} \cdot$ Oscar H. Franco ${ }^{7} \cdot$ Nita G. Forouhi $\mathbb{( D )}^{12} \cdot$ M. Arfan Ikram (1) ${ }^{7}$. \\ Andre G. Uitterlinden $\mathbb{D}^{21}$. Jana V. van Vliet-Ostaptchouk $\mathbb{D}^{22,23} \cdot$ Nick J. Wareham $^{12} \cdot$ David Cesarini $^{24}$. \\ K. Paige Harden ${ }^{25}$. James J. Lee $\mathbb{B}^{26} \cdot$ Daniel J. Benjamin $\mathbb{E}^{6,27,28} \cdot$ Carson C. Chow ${ }^{29} \cdot$ Philipp D. Koellinger ${ }^{1}$
}

Received: 14 October 2018 / Revised: 3 February 2020 / Accepted: 20 February 2020 / Published online: 11 May 2020

(c) The Author(s) 2020. This article is published with open access

\begin{abstract}
We conducted genome-wide association studies (GWAS) of relative intake from the macronutrients fat, protein, carbohydrates, and sugar in over 235,000 individuals of European ancestries. We identified 21 unique, approximately independent lead SNPs. Fourteen lead SNPs are uniquely associated with one macronutrient at genome-wide significance $\left(P<5 \times 10^{-8}\right)$, while five of the 21 lead SNPs reach suggestive significance $\left(P<1 \times 10^{-5}\right)$ for at least one other macronutrient. While the phenotypes are genetically correlated, each phenotype carries a partially unique genetic architecture. Relative protein intake exhibits the strongest relationships with poor health, including positive genetic associations with obesity, type 2 diabetes, and heart disease $\left(r_{g} \approx 0.15-0.5\right)$. In contrast, relative carbohydrate and sugar intake have negative genetic correlations with waist circumference, waist-hip ratio, and neighborhood deprivation $\left(\left|r_{g}\right| \approx 0.1-0.3\right)$ and positive genetic correlations with physical activity $\left(r_{g} \approx 0.1\right.$ and 0.2). Relative fat intake has no consistent pattern of genetic correlations with poor health but has a negative genetic correlation with educational attainment $\left(r_{g} \approx-0.1\right)$. Although our analyses do not allow us to draw causal conclusions, we find no evidence of negative health consequences associated with relative carbohydrate, sugar, or fat intake. However, our results are consistent with the hypothesis that relative protein intake plays a role in the etiology of metabolic dysfunction.
\end{abstract}

Members of 23andMe Research Team, and Lifelines Cohort Study are listed in Supplementary Information 13.2.

Supplementary information The online version of this article (https:// doi.org/10.1038/s41380-020-0697-5) contains supplementary material, which is available to authorized users.

S. Fleur W. Meddens

s.f.w.meddens@vu.nl

$\triangle$ Carson C. Chow

carsonc@niddk.nih.gov

$\triangle$ Philipp D. Koellinger

p.d.koellinger@vu.nl

Extended author information available on the last page of the article

\section{Introduction}

Understanding the relationships between nutrition, lifestyle, and health is among the highest priorities for public health [1]. Many aspects of dietary intake have been studied, but the health impacts of macronutrient composition (i.e. relative intake from fat, protein, and carbohydrate) have been especially controversial in the last few decades [2-4]. Despite a lack of robust empirical evidence from randomized trials on the long-term effects of macronutrient restriction on body weight and health [5-7], dietary recommendations have shifted from low-fat to low-sugar and, more recently, lower animal-protein diets [8-13]. Connections between diet and mental health are also increasingly recognized [14]. Genetic correlation analysis 
allows links between mental health and dietary intake to be estimated without the need to observe psychiatric measures and macronutrient intake in the same samples. These links can then corroborate existing ideas or fuel new hypotheses about the relationships between diet and mental health.

Previous work has found that diet composition is heritable (range $h^{2}=27-70 \%$ ) [15-17] and may share genetic components with health and lifestyle [18]. The largest GWAS on relative intake from protein, fat, and carbohydrates (up to $N=91,114$ ) to date has identified three robustly associated SNPs in or near RARB, FTO, and $F G F 21$, each of which captures only a miniscule part of trait heritability $\left(R^{2}<0.06 \%\right)[19-21]$. These results suggest that diet composition is a genetically complex phenotype that requires large GWAS sample sizes for robust genetic discovery. However, proper measurement of nutrient intake requires a long and detailed questionnaire [22]. Therefore, relatively few large genotyped cohorts have collected this information, which restricts available GWAS sample sizes.

Here, we perform the largest dietary intake GWAS to date, using the vast majority of currently available European-ancestry genotyped diet data. Power calculations determined a minimum required sample size of $N=$ 141,000 (Supplementary Information 1.3). We nearly triple the GWAS sample size compared to earlier work [21] to $N=264,181$ for relative intake of protein, carbohydrate, and fat, increasing the number of robustly associated independent loci from three to 18. Furthermore, we report the first GWAS results for relative sugar intake $(N=230,648)$, which is a subcomponent of our carbohydrate phenotype and captures relative intake of both naturally occurring and added sugars. The sugar GWAS identifies three additional, unique lead loci. In our largest dataset, the UK Biobank $(N=173,253)$ [23], we also report an auxiliary GWAS for saturated fat intake, a subcomponent of our fat phenotype, which we only use for genetic correlation analyses. We also report phenotypic associations between BMI and macronutrient subtypes (plant vs. animal-protein; saturated vs. unsaturated fat; natural vs. added sugars).

Biological annotation of our GWAS results indicates that the brain is the main driver of diet composition's genetic signal. Furthermore, we find robust genetic and phenotypic associations between relative protein intake and poor health, but no clear pattern of associations of the other macronutrients with health. Finally, we probe the robustness of these results to possible confounds due to socioeconomic status and physical activity.

\section{Methods}

This article is accompanied by a Supplementary Information, which describes further methodological details.

\section{Phenotype definitions, GWAS, quality control, and meta-analysis}

We performed GWAS in European-ancestry individuals for four dietary composition phenotypes: relative intake of fat, carbohydrate, and sugar. As an auxiliary analysis, we performed GWAS for relative intake of saturated fat in the UKB. Discovery analyses were performed in UKB, while replication analyses were conducted in cohorts from the Netherlands (Lifelines, RSI/II/III), UK (ALSPAC, Fenland), USA (FHS, HRS, GARNET, HIPFX, WHIMS+), and the international consortia EPIC-InterAct and DietGen (Supplementary Information 1 and Supplementary Table 1.1). Since DietGen only analyzed fat, protein, and carbohydrate intake (measured by DietGen with intake as a percentage of total energy intake), our final sample sizes are $N_{\text {sugar }}=235,391 \quad$ and $\quad N_{\text {fat }}=N_{\text {protein }}=N_{\text {carbohydrate }}=$ 268,922. A study flowchart is presented in Extended Data Fig. 2, which shows that we used the meta-analysis results of UKB + replication cohorts throughout our investigations except for the replication and sensitivity analyses and the auxiliary GWAS for saturated fat.

Cohorts measured previous-day (UKB) or habitual (all other cohorts) dietary intake with comprehensive fooditem questionnaires (Supplementary Table 1.2). Phenotype definitions are described in Supplementary Information 2. With the exception of DietGen, all cohorts corrected macronutrient intakes for total energy intake allowing for nonlinear effects, and GWAS was performed according to a prespecified analysis plan (Supplementary Information 2.6).

Cohort-level quality-control (QC) was performed in accordance with protocols developed by the GIANT consortium [24] and the Social Science Genetic Association Consortium (SSGAC, Supplementary Information 3.3). Filters for participants and SNPs varied by cohort and cohort sample size. SNP effects were summarized across cohorts using fixed-effects sample-size-weighted metaanalyses based on Z-statistics. For the family cohorts UKB and FHS, we used the median effective sample size as a weight (Supplementary Information 3.4).

\section{Replication}

We assess the credibility of individual SNPs from our discovery GWAS by replicating the associations of its lead SNPs in our replication GWAS (Supplementary Information 4, Supplementary Information 4.1). Our replication analyses closely followed the procedure outlined in Supplementary Information section 1.8 of Okbay et al. [25]. We conducted one-sided binomial tests for both the sign concordance of the lead SNPs and the number of lead SNPs from our discovery GWAS that differ at the $P<0.05$ threshold (both with and without Bonferroni correction) in 
the replication GWAS. In addition to conducting binomial tests, we simulated the expected rate of replication given the discovery GWAS results, the discovery sample size and the replication sample size, and we assessed whether these expected rates matched the observed replication rates. We used bivariate LD Score regression to examine the comparability between the summary statistics from our discovery cohort, the 14 replication cohorts, and DietGen (Supplementary Table 4.2). We also report the replication record of a rare variant in DRAMI discovered by Merino et al. [21] (Supplementary Table 4.3).

\section{Population stratification}

LD Score regression was used to estimate inflation of the GWAS results due to population stratification (Supplementary Table 5.1). We adjusted the reported standard errors and $P$-values of meta-analyzed SNPs for bias due to population stratification by dividing them by the square root of the LD Score regression intercept. To identify approximately independent lead SNPs, we applied the clumping algorithm in PLINK (parameters $r^{2}>0.1, P$-value $<5 \times$ $10^{-8}$ ). Supplementary Tables 5.2 and 5.4 report the lead SNPs and the overlapping loci between phenotypes.

\section{Sensitivity analyses}

We performed sensitivity analyses for the two SNPs that reached genome-wide significance in APOE (rs429358) and $A D H 1 B$ (rs1229984, Supplementary Table 5.5). For the $A P O E$ SNP, we assessed its effect size and confidence interval in a subsample of the UKB aged below 60 years. For the $A D H 1 B$ SNP, we assessed its effect size and confidence interval in a subsample of the UKB who report to be non-drinkers. We tested whether the confidence intervals of the effect sizes overlap with the confidence intervals in the meta-analyzed sample.

\section{Biological annotation}

All bioinformatics analyses used the results of the combined meta-analysis (Supplementary Information 6). To annotate the top GWAS findings, we performed MAGMA [26] genebased analysis to test 18,224 genes for association with diet composition (Bonferroni-corrected $P$-value threshold $=$ $0.05 / 18,224)$. To gain preliminary insights into the likely functions of the significant MAGMA genes, we queried them in Gene Network. To gain insights into probable functional genomic categories and tissues, we estimated stratified LD Score regressions for the 52 functional genomic regions of the "baseline model", the 10 broad tissuelevel annotations from Finucane et al. [27], and the 53 fine tissue-level annotations from GTEx, with Bonferroni- corrected $P$-value thresholds $=0.05 / 53,0.05 / 10,0.05 / 52$, respectively (Supplementary Tables 6.1-6.3). To annotate the lead GWAS SNPs, we queried whether they (or SNPs in LD with them) are associated with gene expression in relevant GTEx tissues, or in LD with protein-altering SNPs (Supplementary Tables 6.3-6.6).

\section{Estimation of genome-wide SNP heritability}

We used GCTA-GREML [28] and LD Score regression [29] to estimate the SNP-based heritability of diet composition (Supplementary Information 8, Supplementary Table 8.1). We restricted the GCTA analysis to genotyped SNPs with MAF $>0.01$ and a random subset of 30,000 $\mathrm{UKB}$ individuals in the UKB, and thereafter drop one individual in each pair of individuals with a cryptic relatedness exceeding 0.025 , resulting in $N=28,635$. For the LD Score regression analysis, we used the full metaanalysis results, HapMap3 SNPs with MAF > 0.01, and LD estimates from the 1000 Genomes project provided by Finucane et al. [27].

\section{Genetic correlations between macronutrients}

We used bivariate LD Score regression to estimate the genetic correlations between macronutrients (Supplementary Information 7).

\section{Polygenic prediction}

We assessed the accuracy of polygenic scores of diet composition in the HRS and RSI validation cohorts and used LDpred [30] to construct polygenic scores assuming an underlying infinitesimal model (Supplementary Information 9, Supplementary Table 9.1). Since these cohorts are included in the full meta-analysis, we conducted a new meta-analysis that excludes the holdout cohort to obtain the SNP weights. Analyses are restricted to HapMap3 SNPs with MAF $>0.05$, and LD scores were calculated on the basis of the holdout cohort. Our measure of a score's predictive power is the incremental adjusted $R^{2}$ from adding the score to a regression of the phenotype on the covariates sex, birth-year, birth-year squared, and cubed, as well as the interactions between sex and the three birth-year variables, and the first ten principal components of the genetic relatedness matrix. We bootstrapped $95 \%$ percentile confidence intervals for the incremental $R^{2}$ estimates with 1000 iterations.

\section{Genetic correlations}

We used bivariate LD Score regression to estimate genetic correlations between: diet composition and various health 
and behavioral phenotypes (Supplementary Information 10, Supplementary Tables 10.2-10.4). We used the 1000 Genomes LD scores computed by Finucane et al. [27] and restricted analyses to HapMap3 SNPs with MAF $>0.01$.

\section{Phenotypic associations}

We examined the phenotypic associations between relative macronutrient intake and BMI in four large, independent cohorts from the UK and US (UKB, HRS, FHS, and WHI, with combined $N=173,165$; Supplementary Information 11, Supplementary Table 11.1). In the HRS, FHS, and WHI, we were also able to distinguish animal vs. plant protein, natural vs. added sugars, and saturated vs. unsaturated fat. In the UKB, only the distinction between saturated vs. unsaturated fat was available (Supplementary Table 11.2). We estimated the standardized regression coefficients obtained from a multiple regression of BMI on the focal macronutrient, sex, age, educational attainment, household income (available for all cohorts except FHS), and the number of dietary measurements. In the UKB, we performed an additional regression that included a measure of physical activity. We restricted the samples to individuals also included in the GWAS. We used Fisher's Z-transformation to perform fixed-effects, inverse-variance weighted meta-analysis of the standardized regression coefficients. Fisher's Z-transformation was also used to obtain $95 \%$ confidence intervals.

\section{Results}

\section{Phenotype definition}

All cohorts used self-report questionnaires containing $\geq 70$ food items. Average intakes were highly similar across cohorts (Supplementary Table 1.2). Using these self-reports, we calculated the relative contributions of fat, protein, carbohydrate, and sugar to total energy intake. When possible, we excluded individuals on calorie- or macronutrientrestricted diets (see Supplementary Table 1.3 for all exclusion criteria)

We do not study total energy intake because it is mainly determined by body size and physical activity [31], and because systematic underreporting of total energy intake is correlated with BMI [32]. We caution that selective underreporting of macronutrients could be problematic for the common approach we adopt of studying relative intake, but there is mixed evidence for this, and its consequences are poorly understood (Supplementary Information 2.4).

Since macronutrient intake may not scale linearly with total energy intake, we developed and applied a method that adjusts for observed non-linear relationships
(Supplementary Information 2.6-2.8, Extended Data Fig. 1). Consistent with the satiating properties of protein [33], we find that relative protein intake declines at higher levels of total energy intake, while relative fat intake increases, and relative sugar and carbohydrate intake remain roughly constant (Supplementary Table 2.3).

\section{Main results}

GWAS were performed in individuals of European ancestries from over 14 population cohorts. Informed consent was obtained by the cohorts for all participants included in the analyses. Association statistics underwent rigorous quality control according to SSGAC guidelines [25, 34, 35], which included sample-size-dependent quality-control filters, exclusion of SNPs with too small standard errors or too large explained phenotypic variance, and visualizations of summary statistics and allele frequencies (Supplementary Information 3.3, Supplementary Tables 3.1-3.5). Our discovery sample is the subset of the UKB with survey data on dietary intake $(N=175,253)$. The replication phase consists of a meta-analysis of GWAS summary statistics from 14 additional cohorts that followed our analysis plan $(N=$ $60,138)$ together with summary statistics from DietGen [20] (for fat, protein, and carbohydrate, $N=33,531$, flowchart in Extended Data Fig. 2). DietGen [20] assumed a linear scaling of macronutrients with total energy intake. Nonetheless, we included DietGen in our meta-analysis because the genetic correlations between DietGen and our other replication cohorts are not significantly different from one at $P<0.05$ (Supplementary Table 4.1).

The discovery stage identified 21 approximately independent genome-wide-significant lead SNPs (see Supplementary Information 3.3.5 for a description of the clumping algorithm): 4 for fat, 5 for protein, 5 for sugar, and 7 for carbohydrate (Supplementary Table 4.2). These lead SNPs partially overlap across phenotypes and reside in 14 unique loci. In the replication stage, all 21 lead SNPs had the anticipated signs and comparable effect sizes (Extended Data Fig. 3), and 15 reach statistical significance at $P<0.05$ (Supplementary Table 4.2). This empirical replication record matches or exceeds theoretical predictions that take into account the statistical winner's curse, sampling variation, and statistical power [25] (Supplementary Table 4.1). In our data, the association between DRAMI and dietary intake reported by Merino et al. [21] does not replicate, with a discordant effect size compared to Merino et al. $(\hat{\beta}=-0.028, S E=0.025$ compared to Merino et al.'s $\hat{\beta}=0.122, S E=0.02$ in phenotypic standard deviations per effect allele, Supplementary Table 4.3).

In order to maximize statistical power, all follow-up analyses below are based on the combined discovery and replication samples $(N=235,391-268,922$, Supplementary 
Table 1 Diet composition lead SNPs.

\begin{tabular}{|c|c|c|c|c|c|c|c|}
\hline Top hit in locus for & SNPID & CHR & $\mathrm{BP}$ & Effect allele & Beta & $P$-value & Nearest gene \\
\hline Protein & rs780094 & 2 & $27,741,237$ & $\mathrm{t}$ & 0.018 & $5.58 \mathrm{E}-10$ & $G C K R$ \\
\hline Sugar & rs 12713415 & 2 & $60,205,134$ & $\mathrm{c}$ & -0.019 & 4.88E-09 & AC007100.1 \\
\hline Carbohydrate & rs10206338 & 2 & $60,209,981$ & $\mathrm{a}$ & -0.016 & $1.52 \mathrm{E}-08$ & AC007100.1 \\
\hline Protein & rs 445551 & 2 & $79,697,982$ & $\mathrm{a}$ & 0.019 & $1.49 \mathrm{E}-08$ & CTNNA2 \\
\hline Carbohydrate & rs 10510554 & 3 & $25,099,776$ & $\mathrm{t}$ & 0.019 & $2.94 \mathrm{E}-12$ & AC133680.1 \\
\hline Protein & rs1603978 & 3 & $25,108,236$ & $\mathrm{a}$ & 0.019 & $1.35 \mathrm{E}-10$ & AC092422.1 \\
\hline Sugar & rs7619139 & 3 & $25,110,415$ & $\mathrm{a}$ & -0.024 & $4.98 \mathrm{E}-16$ & AC092422.1 \\
\hline Carbohydrate & rs 10433500 & 3 & $85,546,798$ & $\mathrm{a}$ & 0.016 & $1.96 \mathrm{E}-08$ & $C A D M 2$ \\
\hline Protein & rs13146907 & 4 & $39,425,248$ & $\mathrm{a}$ & -0.022 & $1.24 \mathrm{E}-14$ & $K L B$ \\
\hline Fat & rs 1229984 & 4 & $100,239,319$ & $\mathrm{t}$ & 0.098 & $2.64 \mathrm{E}-28$ & $A D H 1 B$ \\
\hline Sugar & rs 13202107 & 6 & $51,395,463$ & $\mathrm{a}$ & -0.020 & $1.77 \mathrm{E}-08$ & SNORD66 \\
\hline Fat & rs57193069 & 7 & $1,862,417$ & $\mathrm{a}$ & -0.016 & $1.80 \mathrm{E}-08$ & $M A D 1 L 1$ \\
\hline Carbohydrate & rs7012637 & 8 & $9,173,209$ & $\mathrm{a}$ & 0.017 & $4.68 \mathrm{E}-10$ & AC022784.6 \\
\hline Fat & rs7012814 & 8 & $9,173,358$ & $\mathrm{a}$ & -0.019 & $1.12 \mathrm{E}-11$ & AC022784.6 \\
\hline Sugar & rs7012814 & 8 & $9,173,358$ & $\mathrm{a}$ & 0.019 & $4.99 \mathrm{E}-10$ & AC022784.6 \\
\hline Carbohydrate & rs9987289 & 8 & $9,183,358$ & $\mathrm{a}$ & -0.026 & 4.64E-08 & AC022784.6 \\
\hline Protein & rs1461729 & 8 & $9,187,242$ & $\mathrm{a}$ & 0.032 & $4.09 \mathrm{E}-12$ & AC022784.6 \\
\hline Carbohydrate & rs10962121 & 9 & $15,702,704$ & $\mathrm{t}$ & -0.015 & $3.40 \mathrm{E}-08$ & $C C D C 171$ \\
\hline Carbohydrate & rs2472297 & 15 & $75,027,880$ & $\mathrm{t}$ & -0.018 & $3.73 \mathrm{E}-08$ & CYP1A1 \\
\hline Protein & rs55872725 & 16 & $53,809,123$ & $\mathrm{t}$ & 0.018 & $2.09 \mathrm{E}-10$ & FTO \\
\hline Sugar & rs9972653 & 16 & $53,814,363$ & $\mathrm{t}$ & -0.020 & $1.53 \mathrm{E}-11$ & FTO \\
\hline Fat & rs9927317 & 16 & $53,820,996$ & $\mathrm{c}$ & -0.024 & 4.77E-12 & FTO \\
\hline Carbohydrate & rs7190396 & 16 & $53,822,502$ & $\mathrm{t}$ & 0.018 & $2.39 \mathrm{E}-10$ & FTO \\
\hline Carbohydrate & rs1104608 & 16 & $73,912,588$ & $\mathrm{c}$ & 0.018 & $1.74 \mathrm{E}-10$ & AC087565.1 \\
\hline Carbohydrate & rs 36123991 & 17 & $44,359,663$ & $\mathrm{t}$ & 0.021 & 8.24E-09 & $A R L 17 B$ \\
\hline Sugar & rs8097672 & 18 & $1,839,601$ & $\mathrm{a}$ & 0.030 & $1.54 \mathrm{E}-12$ & AP005230.1 \\
\hline Carbohydrate & rs8097672 & 18 & $1,839,601$ & a & 0.023 & $1.95 \mathrm{E}-09$ & AP005230.1 \\
\hline Sugar & rs341228 & 18 & $6,395,336$ & $\mathrm{t}$ & 0.019 & 2.72E-09 & L3MBTL4 \\
\hline Fat & rs429358 & 19 & $45,411,941$ & $\mathrm{t}$ & 0.024 & $8.65 \mathrm{E}-10$ & $A P O E$ \\
\hline Sugar & rs429358 & 19 & $45,411,941$ & $\mathrm{t}$ & -0.028 & $2.97 \mathrm{E}-11$ & $A P O E$ \\
\hline Carbohydrate & rs 429358 & 19 & $45,411,941$ & $\mathrm{t}$ & -0.027 & $3.49 \mathrm{E}-12$ & $A P O E$ \\
\hline Fat & rs33988101 & 19 & $49,218,111$ & $\mathrm{t}$ & -0.029 & $1.66 \mathrm{E}-26$ & MAMSTR \\
\hline Sugar & rs838144 & 19 & $49,250,239$ & $\mathrm{t}$ & -0.028 & $8.53 \mathrm{E}-21$ & IZUMOI \\
\hline Carbohydrate & rs838144 & 19 & $49,250,239$ & $\mathrm{t}$ & -0.023 & $3.26 \mathrm{E}-17$ & IZUMOI \\
\hline Protein & rs838133 & 19 & $49,259,529$ & $\mathrm{a}$ & -0.032 & $4.52 \mathrm{E}-26$ & $F G F 21$ \\
\hline Sugar & rs62132802 & 19 & $49,270,872$ & $\mathrm{t}$ & -0.020 & $1.07 \mathrm{E}-08$ & $F G F 21$ \\
\hline
\end{tabular}

GWAS summary statistics of the 36 diet composition lead SNPs. A total of 21 of these lead SNPs are approximately independent. Supplementary Table 5.1 reports the effect alleles and summary statistics across all four phenotypes for each individual lead SNP. MAF = minor allele frequency (weighted average across cohorts). Beta $=$ increase in phenotypic standard deviations per effect allele. All $P$-values are calculated using standard errors that have been inflated by the estimated LDSC intercept.

Information 5). The quantile-quantile plots exhibit substantial inflation $\left(\lambda_{\mathrm{GC}}=1.12-1.19\right.$, Extended Data Fig. 4). The estimated intercepts from LD Score (LDSC) regressions [29] suggest that the vast majority of this inflation is due to polygenic signal, and only a small share is attributable to population stratification (the maximum estimate, $\sim 6 \%$, is for fat and is not statistically distinguishable from $0 \%$ at $P<0.05$; Supplementary Table 5.1). The number of approximately independent lead SNPs in the combined sample is 36 (pairwise $r^{2}<0.01$ ), including 6 for fat, 7 for protein, 10 for sugar, and 13 for carbohydrate (Table 1, Fig. 1). These 36 reside in 21 unique loci (Supplementary Table 5.4). Fourteen lead SNPs are uniquely associated with one macronutrient at genome-wide significance $(P<x$ $\left.10^{-8}\right)$, while five of these reach suggestive significance $(P<$ $1 \times 10^{-5}$ ) for at least one other macronutrient. The SNP 

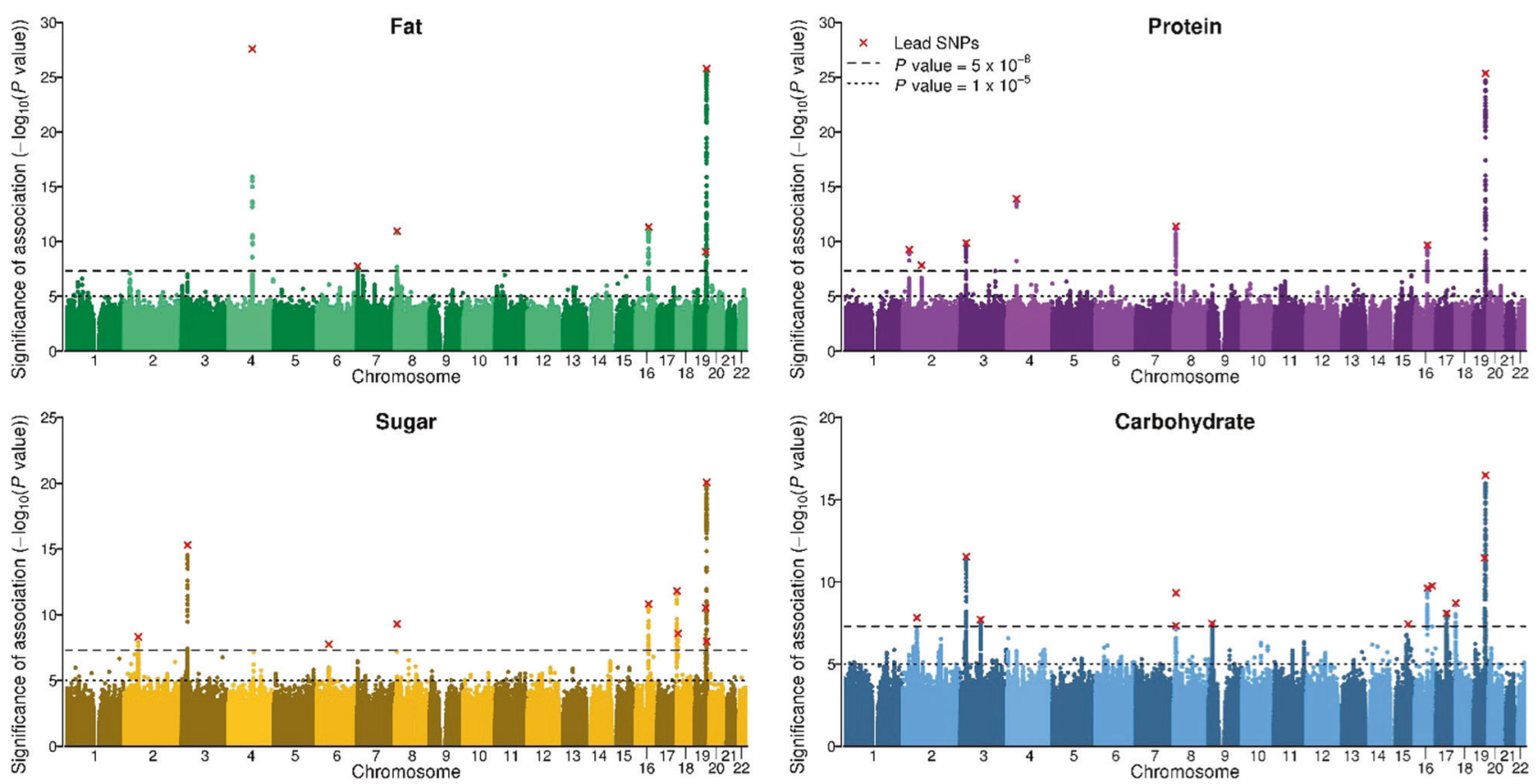

Fig. 1 Manhattan plots. The $x$-axis is SNP chromosomal position; the $y$-axis is the SNP $P$-value on a $-\log _{10}$ scale; the horizontal dashed line marks the threshold for genome-wide $\left(P=5 \times 10^{-8}\right)$ and suggestive

$\left(P=1 \times 10^{-5}\right)$ significance; and each approximately independent (pairwise $r^{2}<0.1$ ) genome-wide significant association ("lead SNP") is marked by a red cross.

effect sizes range from 0.015 to 0.098 phenotypic standard deviations per allele. The phenotypic variance explained per SNP, expressed in terms of coefficient of determination $\left(R^{2}\right)$, ranged from $0.011 \%$ to $0.054 \%$, the same order of magnitude as the $R^{2}$ s of the most strongly associated lead SNPs for other genetically complex traits such as BMI and educational attainment (Extended Data Fig. 5).

MAGMA [26] gene-based analyses of our GWAS summary statistics identifies 81 unique genes (Extended Data Fig. 6 and Supplementary Table 5.5). While the majority of these genes are near our lead SNPs, MAGMA also identifies 33 genomic regions harboring 44 unique genes that are physically distant $(>1 \mathrm{Mb})$ from our lead SNPs.

\section{Discussion of lead SNPs from combined meta- analysis}

Seven of the 21 lead SNPs had not been (directly or via LD partners, $r^{2} \geq 0.6$ and distance $<250 \mathrm{~kb}$ ) associated with any other traits in the NHGRI-EBI GWAS Catalog at the time of query (September 19, 2017) [36] (Supplementary Table 5.6). Each of these seven SNPs is located in or near genes that have not been studied in depth to date.

Five lead SNPs are located in or near genes that have well characterized biological functions in nutrient metabolism or homeostasis but have not previously been associated with dietary intake. First, we find that a missense variant in APOE (rs429358) is associated with fat, sugar,

and carbohydrate, where the allele that decreases Alzheimer's risk is associated with greater relative fat and lower relative sugar and carbohydrate intakes. In addition to its strong association with Alzheimer's disease [37], APOE is known to be involved in fatty acid metabolism. We explored whether the associations in our data may be driven by sample selection. Specifically, older people with dementia may be systematically missing from the UKB, and unaffected elderly people may have different eating habits than younger people. To test for this possibility, we examined the subsample of UKB participants aged below 60 , where such sample selection should be largely absent. We find that the association is indeed smaller in this subsample, but the $95 \%$ confidence interval of the effect size overlaps with that of the effect size in the subsample of UKB participants aged 60 and older (Supplementary Table 5.7).

Second, a well-known missense variant (rs1229984 in $A D H 1 B)$ that limits alcohol metabolism is positively associated with fat intake. The association is weaker in a sample of UKB alcohol abstainers $(N=39,679$; Supplementary Table 5.7), suggesting that it may be partially driven by substitution of fat for alcohol.

Third, one of the protein lead SNPs (rs13146907) is in $K L B$, which codes an essential cofactor to FGF21 [38, 39], which influences sweet and alcohol taste preference via the liver-brain-endocrine axis [40-42]. KLB is only associated with protein in our GWAS and MAGMA analyses, while FGF21 is strongly associated with all four macronutrients in 
both the GWAS and MAGMA analyses. With MAGMA, we also identified MLXIPL (only for fat), a gene that codes a transcription factor to FGF21 [43]. This combination of findings suggests that different genes involved in the same pathway are important for directing intake of different macronutrients.

Fourth, an intergenic variant (rs2472297) that has been linked to higher caffeine consumption $[44,45]$ is associated with lower carbohydrate intake. There are various possible explanations, such as interrelated lifestyle choices pertaining to food and caffeinated drinks.

Fifth, an intronic variant in GCKR (rs780094), a carbohydrate-metabolism gene, is associated with protein. The lead SNP is in almost perfect $\operatorname{LD}\left(r^{2}=0.94\right)$ with a missense variant that has been associated with lipid levels [46] and type 2 diabetes [47].

\section{Bioinformatic analyses}

Animal studies indicate that the brain and peripheral organs interact in directing macronutrient intake [48, 49]. A question that arises is whether the "periphery", which digests and metabolizes macronutrients, plays a larger role than the brain, for instance by determining how the brain assigns reward values to macronutrients. (For example, this is partially the case with alcohol, where mutations that affect metabolic capacity render alcohol consumption unpleasant $[50,51]$.) While individual loci associated with dietary intake have been studied previously (e.g., [21, 52]), it is unknown in which tissues the polygenic signal is enriched. To address this question, we used stratified LDSC $[27,53]$ to identify in which tissues diet-compositionassociated SNPs are likely to be expressed (Supplementary Information 6.1). We performed two stratified LDSC analyses, which partitioned SNP heritability according to (i) 10 broadly-defined tissues, which were ascertained with LDSC reference data from chromatin data [54] and (ii) 53 tissues (including 14 brain regions), as ascertained with LDSC reference data from sets of Specifically Expressed Genes in GTEx (known as LDSC-SEG) [53]. To correct for multiple testing across tissues, we used Bonferroni-adjusted significance thresholds for the number of tested tissues $(\alpha=$ $0.05 / 10=0.005$ and $\alpha=0.05 / 53=9.4 \times 10^{-4}$, respectively).

We find that the central nervous system explains the majority of the genetic signal for all macronutrients (for the regression coefficients; Fig. 2), with the proportions of explained heritability ranging from $44 \%$ (fat and sugar) to $55 \%$ (protein). Within the central nervous system, we find broad involvement of the brain, including (frontal) cortex (fat and sugar), the basal ganglia (fat), limbic system (fat and sugar), cerebellum (protein), and hypothalamus and substantia nigra for fat and protein (and sugar only suggestively after Bonferroni correction). The confidence

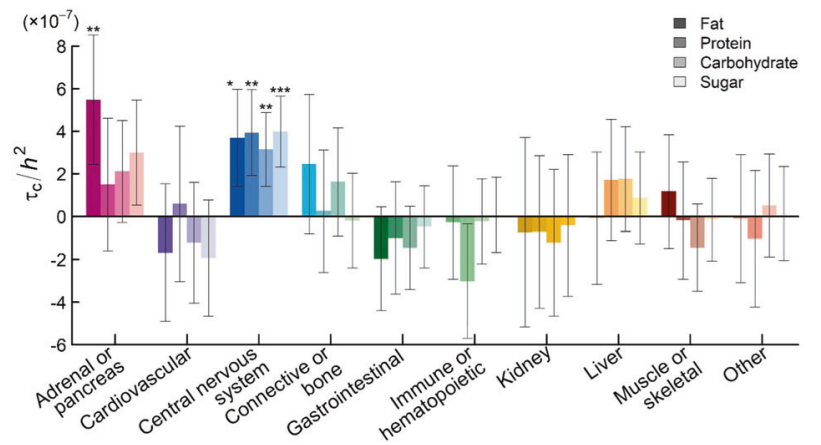

Fig. 2 LD Score partitioning of heritability. Functional partitioning of the heritability of diet-composition phenotypes with stratified LD Score regression, where tissues were ascertained by Finucane et al. on the basis of chromatin data. The panel shows the partial regression coefficient $\left(\tau_{C}\right)$ from the stratified regression, divided by the LD Score heritability of the diet-composition phenotype $\left(h^{2}\right)$. Error bars depict 95\% confidence intervals. The phenotypes are ordered from left to right (fat, protein, sugar, and carbohydrate), from darker to lighter shades. Asterisks $(*)$ denote significant deviation from zero after Bonferroni correction for 10 tissues: $* P<\frac{0.05}{10}, * * P<\frac{0.01}{10}$, *** $P<\frac{0.001}{10}$.

intervals for the coefficients overlap across brain regions, so we cannot draw conclusions about the specificity of brain regions for intake of particular macronutrients.

For fat, genetic variation related to adrenals and/or pancreas tissue is estimated to explain $37 \%$ of the heritability. Because the adrenals play a role in lipid metabolism, and the pancreas is crucial for digestion, either tissue may plausibly affect fat intake. We caution, however, that in the LDSC-SEG analyses of 53 tissues, all non-brain regions had $P$-values above 0.05 even before Bonferroni adjustment.

To gain insight into the putative functions of the top associated loci, we queried the 81 genes identified by the MAGMA analyses in Gene Network [55], which predicts Reactome [56] functions for genes (Supplementary Information 6.2). In addition to neural functioning (e.g., axon guidance), we find that the MAGMA genes are predicted to be involved in growth factor signaling and the immune system (Supplementary Information 6.6). These results may imply a more pronounced role for peripheral gene functions than our stratified LDSC results, which mainly implicated the brain.

\section{Genetic correlations, heritability estimation, and polygenic prediction}

We estimated pairwise genetic correlations between the macronutrients with bivariate LDSC [57]. All are statistically distinguishable from zero at $P<0.05$ (except fat and protein), but also from one and negative one (Supplementary Information 7.1, Supplementary Information 7). (As we explain in Supplementary Information 2.8, negative phenotypic and genetic correlations are not mechanically 


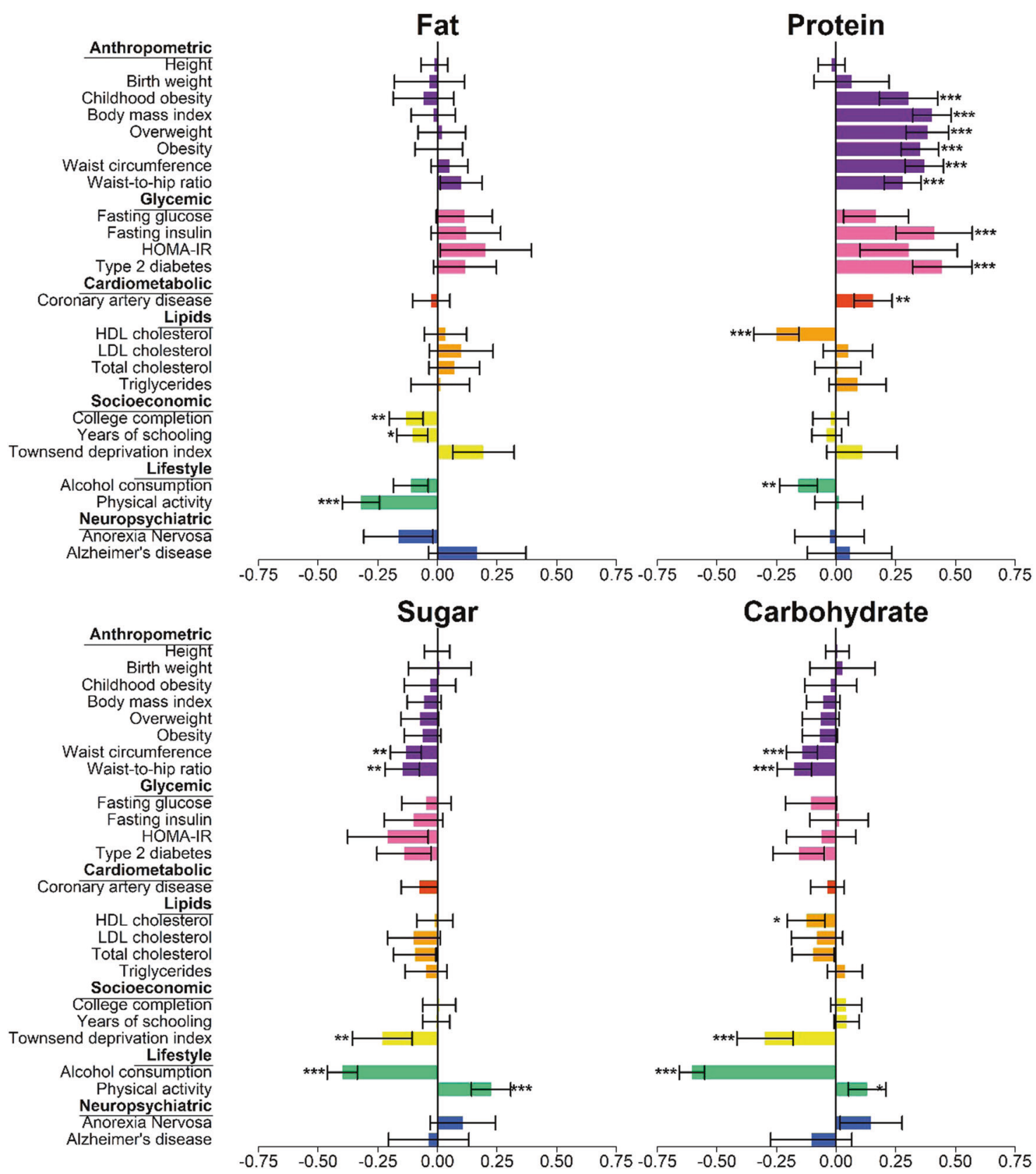

Fig. 3 Genetic correlations. Genetic correlations were estimated with bivariate LD Score (LDSC) regression. Error bars show $95 \%$ confidence intervals, while asterisks denote Bonferroni-corrected $P$-value thresholds $(* P / 33<0.05, * *<0.01, * * *<0.001)$, corrected for 33 traits. The colours represent the different functional domains.

induced by our phenotype definition.) Thus the macronutrients have overlapping but distinct genetic architectures, consistent with previous work from animal studies showing distinct biological mechanisms involved in macronutrientspecific appetites [48].

We calculated GREML [28] estimates of SNP-based heritability using a random $N=30,000$ subsample of conventionally unrelated UKB participants. The estimates range from $2.1 \%$ for protein to $7.9 \%$ for carbohydrate (Extended Data Fig. 7 and Supplementary Table 8.1). Our estimates are similar to previous estimates [20, 21]. These heritability estimates might be biased downward due to phenotypic measurement error (Supplementary Information 8.2) and are similar in magnitude to those from other complex (and also noisily measured) behavioral phenotypes, such as subjective wellbeing [34] and risk preferences [35].

We constructed polygenic scores for the macronutrient intakes by applying LDpred [30] to our GWAS summary statistics. We assessed the scores' out-of-sample predictive 
Fig. 4 Phenotypic associations with body mass index.

Phenotypic associations between diet composition and body mass index (BMI) in four independent cohorts, in terms of standardized regression coefficients (with 95\% confidence intervals). These coefficients were obtained from a regression of BMI on the focal macronutrient and several covariates (sex, age, educational attainment, and household income). FHS Framingham Heart Study $(N=4,413)$, HRS Health and Retirement Study $(N=2,394)$, UKB UK Biobank $(N=158,046)$, WHI Women's Health Initiative $(N=8,628)$.

The summary estimate was based on fixed-effects, inversevariance-weighted metaanalysis.
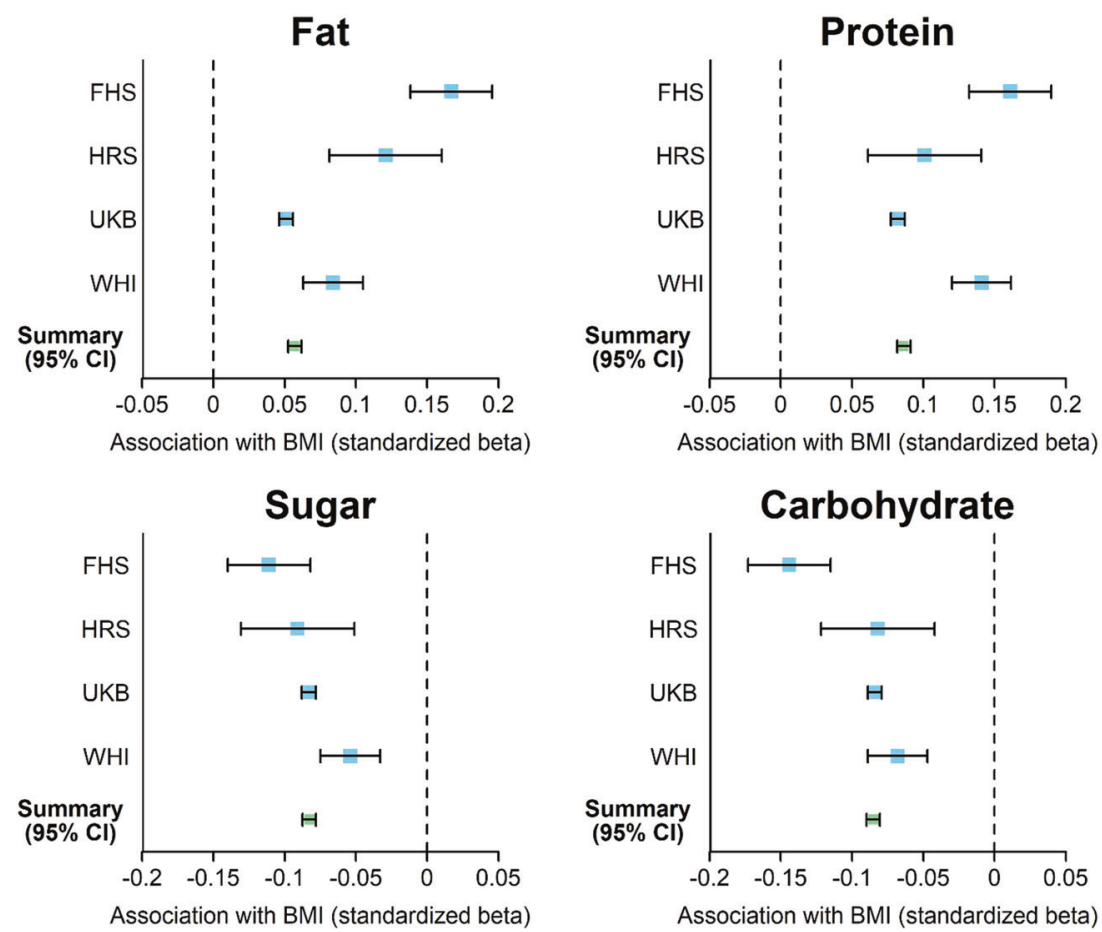

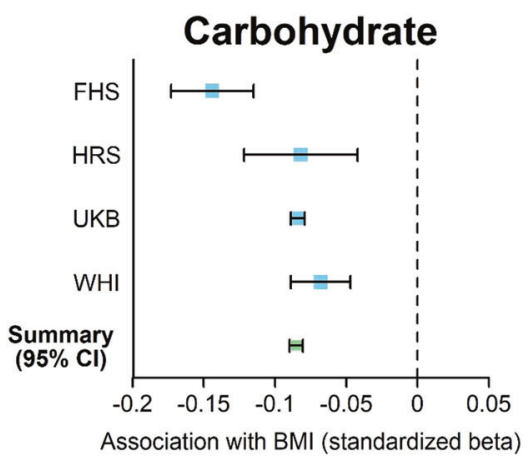

accuracy in two holdout cohorts: The Health and Retirement Study $(N=2,344)$ and the Rotterdam Study $(N=$ $3,585)$. The scores predict the macronutrient intakes with incremental adjusted $R^{2}$ ranging between $0.08 \% \quad(P=$ $0.088)$ and $0.71 \% \quad\left(P=9.11 \times 10^{-7} ; \quad\right.$ Supplementary Table 9.1, Extended Data Fig. 8).

\section{Relationships with health, lifestyle, and socioeconomic status}

Using bivariate LDSC [57, 58], we estimated genetic correlations between our diet-composition phenotypes and 19 preselected relevant medical and lifestyle phenotypes for which well-powered GWAS results were available. We also included four additional phenotypes for which GWAS results became available after our study was underway, as well as Alzheimer's disease, motivated by the association we found between $A P O E$ and macronutrient intakes, and nine phenotypes from the psychiatric domain. To control for multiple testing, we again used Bonferroni-adjusted $P$-value thresholds $(\alpha=0.05 / 33)$.

Protein exhibits the strongest genetic correlations with poor health outcomes, including obesity $\left(r_{g}=0.35, S E=\right.$ $0.04)$, type 2 diabetes $\left(r_{\mathrm{g}}=0.45, S E=0.06\right)$, fasting insulin $\left(r_{g}=0.41, \mathrm{SE}=0.08\right)$, and coronary artery disease $\left(r_{g}=0.16, S E=0.04\right)$, as well as BMI $\left(r_{g}=0.40, S E=\right.$ 0.04) (Fig. 3, Supplementary Table 10.2). Fat, sugar, and carbohydrate has negative, non-significant genetic correlations with BMI ( $r_{g}$ between -0.06 and -0.02). For comparison, we estimated phenotypic associations between diet composition and BMI in four independent cohorts (combined $N=173,353$ ) and meta-analyzed the results (Fig. 4). Protein (standardized $\hat{\beta}=0.090,95 \% \mathrm{CI}$ $[0.085,0.094]$ ) and fat (standardized $\hat{\beta}=0.069,95 \% \mathrm{CI}$ $[0.059,0.067])$ are positively associated with BMI, while sugar and carbohydrate are negatively associated with BMI (standardized $\hat{\beta}=-0.082,95 \%$ CI $[-0.087$, $-0.078]$; and $-0.084,95 \%$ CI $[-0.088,-0.079]$ respectively, Supplementary Table 11.1). Thus, the genetic correlation between protein and BMI stands out as large relative to the phenotypic correlations. The phenotypic association between overall protein intake and BMI is probably driven by animal protein, which has a positive correlation with BMI (standardized $\hat{\beta}=0.16,95 \% \mathrm{CI}$ $[0.15,0.18])$, while plant protein has a negative correlation between BMI (standardized $\hat{\beta}=-0.07$, 95\% CI $[-0.08,-0.05])$. These protein subtypes were available in four population cohorts with a total $N=15,347$. No such large differences are found between natural vs. added sugar and saturated vs. unsaturated fat (Supplementary Table 11.2, Extended Data Fig. 9).

Despite their relatively weak genetic correlations with BMI, sugar, and carbohydrate have negative genetic correlations with waist circumference $\left(r_{g}=-0.13, S E=0.03\right.$, and $\left.r_{g}=-0.14, S E=0.03\right)$ and waist-hip ratio $\left(r_{g}=-0.15\right.$, $S E=0.04$, and $\left.r_{g}=-0.18, S E=0.04\right)$ that are larger in magnitude and statistically distinguishable from zero at the $5 \%$ level. All the macronutrients have negative genetic correlations with alcohol consumption ( $r_{g}$ between -0.61 and -0.11 , as expected since alcohol is included in energy 
intake and our phenotype measures are shares of energy intake (Supplementary Information 2.8).

Next, we computed genetic correlations with indicators of socioeconomic status [25, 59, 60], which are heritable [59, 60] and known to be phenotypically associated with food access, dietary choices, and health [61-65]. We found that fat is negatively genetically correlated with educational attainment $\left(r_{g}=-0.13, S E=0.04\right)$. Sugar and carbohydrate are negatively genetically correlated with the Townsend deprivation index $\left(r_{g}=-0.23, S E=0.06\right.$ and $-0.30, S E=$ 0.06), which is constructed from the rates of unemployment, non-ownership of cars and houses, and neighborhood overcrowding [60, 66], with higher scores indicating more severe socioeconomic deprivation. These genetic correlations might hint at environmental factors involved in macronutrient intake, although these relationships might also be caused by unmeasured, confounding factors.

Finally, we estimate the genetic correlations between diet composition and physical activity, which has widespread physical and mental health benefits [67, 68]. In these genetic correlation analyses, we used unpublished physical activity GWAS summary statistics from a sample of research participants from 23andMe $(N=269,189)$. The physical activity phenotype is a composite measure based on self-reported activities from leisure, occupation, and commuting. We find a negative genetic correlation of physical activity with fat $\left(r_{g}=-0.32, S E=0.04\right)$ and a positive genetic correlation with sugar $\left(r_{g}=0.23, S E=\right.$ $0.04)$ and carbohydrate $\left(r_{g}=0.13, S E=0.04\right)$. The genetic correlation with protein is positive but not statistically distinguishable from zero at $P<0.05\left(r_{g}=0.011\right)$. In the psychiatric domain, we find negative genetic correlations between saturated fat and schizophrenia $\left(r_{g}=-0.13, S E=\right.$ $0.04)$ and between carbohydrate and ADHD $\left(r_{g}=-0.19\right.$, $S E=0.04)$. The negative genetic correlation with schizophrenia contrasts with its known positive phenotypic correlation, as patients with schizophrenia tend to consume higher amounts of saturated fat [69]. The negative genetic correlation with ADHD might be related to ADHD's responsiveness to dietary intervention [70], or might be explained by socioeconomic status.

\section{Discussion}

The genetic correlations we find between protein and obesity, waist-hip ratio, fasting insulin, type 2 diabetes, HDL cholesterol, and heart disease, together with the association we find between the BMI-increasing FTO allele and increased protein intake, point to an intriguing hypothesis: relative protein intake may play a role in the etiology of metabolic dysfunction. This hypothesis coincides with a growing (but often overlooked [71]) body of evidence that links protein intake to obesity and insulin resistance [7280]. There is some related evidence from randomized trials with infants, which found a causal relationship between high-protein baby formula and infant body fat [81]. While the underlying biological mechanisms are unclear, high consumption of protein or certain types of amino acids (i.e., building blocks of protein) is known to induce insulin resistance [82-84], rapamycin signaling [77], and growth factor signaling [85], which might increase metabolic dysfunction and early mortality risk. Indeed, a recent phenotypic meta-analysis of prospective observational studies (pooled $N=154,344$ ) found that low carbohydrate diets, which restrict carbohydrate in favor of increased animal protein or fat intake, were robustly associated with increased mortality [86].

We caution, however, that the strong and consistent links between protein and poor health outcomes might also be consistent with alternative explanations. Causation could run in the reverse direction: overweight individuals may have higher protein needs or use high-protein diets as a weight-loss strategy. The associations might also be caused by other, unmeasured variables such as unhealthy lifestyle factors or co-consumed ingredients. However, we find that the phenotypic association between protein and BMI is robust to controls for educational attainment and household income. Furthermore, the genetic correlation between protein and physical activity is statistically indistinguishable from zero. These findings weigh against socioeconomic status or physical activity being confounders of the positive genetic correlation between protein and BMI. In any case, the consistent associations that we find between protein intake and poor health warrant further attention.

For sugar, the phenotypic and genetic correlations we found with BMI and other health outcomes are consistent with observations from systematic reviews and metaanalyses of phenotypic relationships. These correlations may suggest that dietary sugar, beyond its energy content, does not have negative health effects [87-90], contrary to some popular beliefs (e.g., [91]). Another possibility is that exercise offsets negative metabolic effects of high sugar intake [92, 93]. Those with a higher predisposition to be physically active may tend to consume more sugar, as sugar is a metabolically convenient source of energy during exercise [94] and may enhance endurance [95]. If so, the positive genetic correlation between sugar and physical activity might partially explain the lack of genetic correlations between sugar and poor health.

For fat and carbohydrate, we also find no consistent pattern of genetic and phenotypic associations with poor metabolic health. Taken together, our results complement the findings of phenotypic analyses by the multinational EPIC-PANACEA consortium (pooled $N=373,803$ ), which found that only calories from protein are associated with 
prospective weight gain [96]. While this finding was consistent across 10 countries, we caution that EPIC-PANACEA's evidence, like ours, is limited by its reliance on selfreported eating habits.

Overall, our results show that the relative intake of each macronutrient has a distinct genetic architecture, and the pattern of genetic correlations might be suggestive of health implications beyond total calorie intake. Moreover, our genetic correlation and bioinformatics analyses suggest a number of novel hypotheses regarding the causes and consequences of dietary intake that can be explored in future work.

Acknowledgements This research was carried out under the auspices of the Social Science Genetic Association Consortium (SSGAC, https://www.thessgac.org/). The research has also been conducted using the UK Biobank Resource under Application Number 11425. The study was supported by funding from the Ragnar Söderberg Foundation (E9/11 and E42/15), the Swedish Research Council (4212013-1061), The Jan Wallander and Tom Hedelius Foundation, an ERC Consolidator Grant to Philipp Koellinger (647648 EdGe), the Pershing Square Fund of the Foundations of Human Behavior, The Open Philanthropy Project (2016-152872, 010623-00001), and the NIA/NIH through grants P01-AG005842, P01-AG005842-20S2, P30AG012810, and T32-AG000186-23 to NBER, and R01-AG042568-02 and R56-AG042568-04 to the University of Southern California. CCC was supported by the Intramural Research Program of the NIH/ NIDDK and thanks Kevin Hall for informative discussions. PME was funded by Nestlé Nutrition. We thank the DietGen and CHARGE consortia for sharing diet-composition GWAS summary statistics, and we thank 23 andMe, Inc., for sharing physical activity GWAS summary statistics. A full list of acknowledgements is provided in Supplementary Information 13 .

\section{Compliance with ethical standards}

Conflict of interest The authors declare that they have no conflict of interest.

Publisher's note Springer Nature remains neutral with regard to jurisdictional claims in published maps and institutional affiliations.

Open Access This article is licensed under a Creative Commons Attribution 4.0 International License, which permits use, sharing, adaptation, distribution and reproduction in any medium or format, as long as you give appropriate credit to the original author(s) and the source, provide a link to the Creative Commons license, and indicate if changes were made. The images or other third party material in this article are included in the article's Creative Commons license, unless indicated otherwise in a credit line to the material. If material is not included in the article's Creative Commons license and your intended use is not permitted by statutory regulation or exceeds the permitted use, you will need to obtain permission directly from the copyright holder. To view a copy of this license, visit http://creativecommons. org/licenses/by/4.0/.

\section{References}

1. Mozaffarian D, Rosenberg I, Uauy R. History of modern nutrition science-implications for current research, dietary guidelines, and food policy. BMJ. 2018;361:k2392.
2. Hall KD, Guo J. Obesity energetics: body weight regulation and the effects of diet composition. Gastroenterology. 2017;152: 1718-27.

3. Buchholz AC, Schoeller DA. Is a calorie a calorie? Am J Clin Nutr. 2004;79:899S-906S.

4. Feinman RD, Fine EJ. A calorie is a calorie' violates the second law of thermodynamics. Nutr J. 2004. https://doi.org/10.1186/ 1475-2891-3-9.

5. Katz DL, Meller S. Can we say what diet is best for health? Annu Rev Public Health. 2014;35:83-103.

6. Atallah R, Filion KB, Wakil SM, Genest J, Joseph L, Poirier P, et al. Long-term effects of 4 popular diets on weight loss and cardiovascular risk factors: a systematic review of randomized controlled trials. Circ Cardiovasc Qual Outcomes. 2014;7:815-27.

7. Howard BV, Manson JAE, Stefanick ML, Beresford SA, Frank G, Jones B, et al. Low-fat dietary pattern and weight change over 7 years: The Women's Health Initiative Dietary Modification Trial. J Am Med Assoc. 2006;295:39-49.

8. La Berge AF. How the ideology of low fat conquered America. J Hist Med Allied Sci. 2008;63:139-77.

9. WHO. Information note about intake of sugars recommended in the WHO guideline for adults and children. 2015. http://www. who.int/nutrition/publications/guidelines/sugar_intake_informa tion_note_en.pdf. Accessed 1 Mar 2018.

10. U.S. Department of Health and Human Services and U.S. Department of Agriculture. 2015-2020 Dietary Guidelines for Americans. 8th edn. 2015. http://health.gov/dietaryguidelines/ 2015/guidelines/. Accessed 1 Mar 2018.

11. Mozaffarian D, Ludwig DS. The 2015 US Dietary Guidelines. JAMA. 2015;313:2421.

12. Johns DM, Oppenheimer GM. Was there ever really a "sugar conspiracy"? Science. 2018;359:747-50.

13. Koletzko B, Demmelmair H, Grote V, Prell C, Weber M. High protein intake in young children and increased weight gain and obesity risk. Am J Clin Nutr. 2016;103:303-4.

14. Sarris J, Logan AC, Akbaraly TN, Amminger GP, BalanzáMartínez V, Freeman MP, et al. Nutritional medicine as mainstream in psychiatry. Lancet Psychiatry. 2015;2:271-4.

15. Wade J, Milner J, Krondl M. Evidence for a physiological regulation of food selection and nutrient intake in twins. Am J Clin Nutr. 1981;34:143-7.

16. De Castro JM. Heritability of diurnal changes in food intake in free-living humans. Nutrition. 2001;17:713-20.

17. Hasselbalch AL, Heitmann BL, Kyvik KO, Sørensen TIA. Studies of twins indicate that genetics influence dietary intake. J Nutr. 2008;138:2406-12.

18. Martin LJ, Lee SY, Couch SC, Morrison J, Woo JG. Shared genetic contributions of fruit and vegetable consumption with BMI in families $20 \mathrm{y}$ after sharing a household. Am J Clin Nutr. 2011;94:1138-43.

19. Tanaka T, Ngwa JS, Van Rooij FJA, Zillikens MC, Wojczynski MK, Frazier-Wood AC, et al. Genome-wide meta-analysis of observational studies shows common genetic variants associated with macronutrient intake. Am J Clin Nutr. 2013;97:1395-402.

20. Chu AY, Workalemahu T, Paynter NP, Rose LM, Giulianini F, Tanaka T, et al. Novel locus including FGF21 is associated with dietary macronutrient intake. Hum Mol Genet. 2013;22: 1895-902.

21. Merino J, Dashti HS, Li SX, Sarnowski C, Justice AE, Graff M et al. Genome-wide meta-analysis of macronutrient intake of 91,114 European ancestry participants from the cohorts for heart and aging research in genomic epidemiology consortium. Mol Psychiatry. 2019;24:1920-32.

22. Subar AF, Ziegler RG, Thompson FE, Johnson CC, Weissfeld JL, Reding D, et al. Is shorter always better? Relative importance of questionnaire length and cognitive ease on response rates and data 
quality for two dietary questionnaires. Am $\mathrm{J}$ Epidemiol. 2001;153:404-9.

23. Hewitt J, Walters M, Padmanabhan S, Dawson J. Cohort profile of the UK Biobank: diagnosis and characteristics of cerebrovascular disease. BMJ Open. 2016;6:e009161.

24. Winkler TW, Day FR, Croteau-Chonka DC, Wood AR, Locke AE, Mägi R, et al. Quality control and conduct of genome-wide association meta-analyses. Nat Protoc. 2014;9:1192-212.

25. Okbay A, Beauchamp JP, Fontana MA, Lee JJ, Pers TH, Rietveld $\mathrm{CA}$, et al. Genome-wide association study identifies 74 loci associated with educational attainment. Nature. 2016;533:539-42.

26. de Leeuw CA, Mooij JM, Heskes T, Posthuma D. MAGMA: Generalized gene-set analysis of GWAS data. PLoS Comput Biol. 2015;11:e1004219.

27. Finucane HK, Bulik-Sullivan B, Gusev A, Trynka G, Reshef Y, Loh PR, et al. Partitioning heritability by functional annotation using genome-wide association summary statistics. Nat Genet. 2015;47:1228-35.

28. Yang J, Lee SH, Goddard ME, Visscher PM. GCTA: a tool for genome-wide complex trait analysis. Am J Hum Genet. 2011;88:76-82.

29. Bulik-Sullivan BK, Loh P-R, Finucane HK, Ripke S, Yang J, Patterson N, et al. LD Score regression distinguishes confounding from polygenicity in genome-wide association studies. Nat Genet. 2015;47:291-5.

30. Vilhjálmsson BJ, Yang J, Finucane HK, Gusev A, Lindström S, Ripke $\mathrm{S}$, et al. Modeling linkage disequilibrium increases accuracy of polygenic risk scores. Am J Hum Genet. 2015;97:576-92.

31. Mifflin MD, St Jeor ST, Hill LA, Scott BJ, Daugherty SA, Koh YO. A new predictive equation for resting energy expenditure in healthy individuals. Am J Clin Nutr. 1990;51:241-7.

32. Poslusna K, Ruprich J, De Vries JHM, Jakubikova M, Van 't Veer $P$. Misreporting of energy and micronutrient intake estimated by food records and $24 \mathrm{~h}$ recalls, control and adjustment methods in practice. Br J Nutr. 2009;101:S73-S85.

33. Halton TL, Hu FB. The effects of high protein diets on thermogenesis, satiety and weight loss: a critical review. J Am Coll Nutr. 2004;23:373-85.

34. Okbay A, Baselmans BML, De Neve J-E, Turley P, Nivard MG, Fontana MA, et al. Genetic variants associated with subjective well-being, depressive symptoms, and neuroticism identified through genome-wide analyses. Nat Genet. 2016;48:624-33.

35. Karlsson Linnér R, Biroli P, Kong E, Meddens SFW, Wedow R, Fontana MA, et al. Genome-wide association analyses of risk tolerance and risky behaviors in over 1 million individuals identify hundreds of loci and shared genetic influences. Nat Genet. 2019;51:245-57.

36. Welter D, MacArthur J, Morales J, Burdett T, Hall P, Junkins H et al. The NHGRI GWAS Catalog, a curated resource of SNP-trait associations. Nucleic Acids Res. 2014;42:D1001-6.

37. Liu C-C, Kanekiyo T, Xu H, Bu G. Apolipoprotein E and Alzheimer disease: risk, mechanisms and therapy. Nat Rev Neurol. 2013;9:106-18.

38. Ogawa Y, Kurosu H, Yamamoto M, Nandi A, Rosenblatt KP, Goetz R, et al. betaKlotho is required for metabolic activity of fibroblast growth factor 21. Proc Natl Acad Sci USA. 2007; 104:7432-7.

39. Kurosu H, Choi M, Ogawa Y, Dickson AS, Goetz R, Eliseenkova $\mathrm{AV}$, et al. Tissue-specific expression of $\beta \mathrm{klotho}$ and Fibroblast Growth Factor (FGF) receptor isoforms determines metabolic activity of FGF19 and FGF21. J Biol Chem. 2007;282:26687-95.

40. Schumann G, Liu C, O'Reilly P, Gao H, Song P, Xu B, et al. KLB is associated with alcohol drinking, and its gene product $\beta$-Klotho is necessary for FGF21 regulation of alcohol preference. Proc Natl Acad Sci USA. 2016;113:14372-7.
41. Von Holstein-Rathlou S, Bondurant LD, Peltekian L, Naber MC, Yin TC, Claflin KE, et al. FGF21 mediates endocrine control of simple sugar intake and sweet taste preference by the liver. Cell Metab. 2016;23:335-43.

42. Talukdar S, Owen BM, Song P, Hernandez G, Zhang Y, Zhou Y, et al. FGF21 regulates sweet and alcohol preference. Cell Metab. 2016;23:344-9.

43. Adams AC, Gimeno RE. The sweetest thing: regulation of macronutrient preference by FGF21. Cell Metab. 2016;23:227-8.

44. Cornelis MC, Monda KL, Yu K, Paynter N, Azzato EM, Bennett $\mathrm{SN}$, et al. Genome-wide meta-analysis identifies regions on $7 \mathrm{p} 21$ (AHR) and 15q24 (CYP1A2) as determinants of habitual caffeine consumption. PLoS Genet. 2011;7:e1002033.

45. Coffee and Caffeine Genetics Consortium C and CG, Cornelis MC, Byrne EM, Esko T, Nalls MA, Ganna A, et al. Genome-wide meta-analysis identifies six novel loci associated with habitual coffee consumption. Mol Psychiatry. 2015;20:647-56.

46. Chasman DI, Paré G, Mora S, Hopewell JC, Peloso G, Clarke R, et al. Forty-three loci associated with plasma lipoprotein size, concentration, and cholesterol content in genome-wide analysis. PLoS Genet. 2009;5:e1000730.

47. Vaxillaire M, Cavalcanti-proenc C, Tichet J, Marre M, Balkau B, Froguel $\mathrm{P}$, et al. The common $\mathrm{P} 446 \mathrm{~L}$ polymorphism in GCKR inversely modulates fasting glucose and triglyceride levels and reduces type 2 diabetes risk in the DESIR prospective general French population. Diabetes. 2008;57:2253-7.

48. Berthoud HR, Münzberg H, Richards BK, Morrison CD. Neural and metabolic regulation of macronutrient intake and selection. Proc Nutr Soc. 2012;71:390-400.

49. Efeyan A, Comb WC, Sabatini DM. Nutrient-sensing mechanisms and pathways. Nature. 2015;517:302-10.

50. Whitfield JB, Martin NG. Aversive reactions and alcohol use in europeans. Alcohol Clin Exp Res. 1993;17:131-4.

51. Harada S, Agarwal DP, Goedde HW, Tagaki S, Ishikawa B. Possible protective role against alcoholism for aldehyde dehydrogenase isozyme deficiency in Japan. Lancet (Lond, Engl). 1982;2:827.

52. Potthoff MJ. A new frontier in FGF21 biology. Nat Rev Endocrinol. 2017;13:74-76.

53. Finucane HK, Reshef YA, Anttila V, Slowikowski K, Gusev A, Byrnes A, et al. Heritability enrichment of specifically expressed genes identifies disease-relevant tissues and cell types. Nat Genet. 2018;50:621-9.

54. Finucane HK, Bulik-Sullivan B, Gusev A, Trynka G, Reshef Y, Loh P-R, et al. Partitioning heritability by functional category using GWAS summary statistics. Nat Genet. 2015;47:1228-35.

55. Fehrmann RSN, Karjalainen JM, Krajewska M, Westra H-J, Maloney D, Simeonov A, et al. Gene expression analysis identifies global gene dosage sensitivity in cancer. Nat Genet. 2015;47:115-25.

56. Croft D, Mundo AF, Haw R, Milacic M, Weiser J, Wu G, et al. The Reactome pathway knowledgebase. Nucleic Acids Res. 2014;42:D472-7.

57. Bulik-Sullivan BK, Finucane HK, Anttila V, Gusev A, Day FR, Loh P-R, et al. An atlas of genetic correlations across human diseases and traits. Nat Genet. 2015;47:1236-41.

58. Zheng J, Erzurumluoglu AM, Elsworth BL, Kemp JP, Howe L, Haycock PC, et al. LD Hub: a centralized database and web interface to perform LD score regression that maximizes the potential of summary level GWAS data for SNP heritability and genetic correlation analysis. Bioinformatics. 2017;33:272-9.

59. Rietveld CA, Medland SE, Derringer J, Yang J, Esko T, Martin NW, et al. GWAS of 126,559 individuals identifies genetic variants associated with educational attainment. Science. 2013;340:1467-71. 
60. Hill WD, Hagenaars SP, Marioni RE, Harris SE, Liewald DCM, Davies G, et al. Molecular genetic contributions to social deprivation and household income in UK Biobank. Curr Biol. 2016;26:3083-9.

61. Beaulac J, Kristjansson E, Cummins S. A systematic review of food deserts, 1966-2007. Prev Chronic Dis. 2009;6:A105.

62. Handbury Ilya Rahkovsky Molly Schnell J, Currie J, De Loecker J, Duranton G, Gyourko J, Kastl J et al. Is the focus on food deserts fruitless? Retail access and food purchases across the socioeconomic spectrum. NBER Work Pap. 2015. http://www. nber.org/papers/w21126. Accessed 9 Jul 2018.

63. Adler NE, Boyce T, Chesney MA, Cohen S, Folkman S, Kahn RL, et al. Socioeconomic status and health. The challenge of the gradient. Am Psychol. 1994;49:15-24.

64. Marmot MG, Wilkinson RG. Social determinants of health: The solid facts. 2nd edn. World Health Organization; 2003.

65. Stringhini S, Carmeli C, Jokela M, Avendaño M, Muennig P, Guida F, et al. Socioeconomic status and the $25 \times 25$ risk factors as determinants of premature mortality: a multicohort study and meta-analysis of 1.7 million men and women. Lancet. 2017; 389:1229-37.

66. Townsend P. Deprivation. J Soc Policy. 1987;16:125.

67. Reiner M, Niermann C, Jekauc D, Woll A. Long-term health benefits of physical activity - a systematic review of longitudinal studies. BMC Public Health. 2013;13:813.

68. Piercy KL, Troiano RP, Ballard RM, Carlson SA, Fulton JE, Galuska DA, et al. The physical activity guidelines for Americans. JAMA. 2018;320:2020-8.

69. Amani R. Is dietary pattern of schizophrenia patients different from healthy subjects? BMC Psychiatry. 2007;5:3-7.

70. Pelsser LM, Frankena K, Toorman J, Savelkoul HF, Dubois AE, Pereira RR, et al. Effects of a restricted elimination diet on the behaviour of children with attention-deficit hyperactivity disorder (INCA study): $\bar{a}$ randomised controlled trial. Lancet. 2011;377:494-503.

71. Campbell TC. A plant-based diet and animal protein: questioning dietary fat and considering animal protein as the main cause of heart disease. J Geriatr Cardiol. 2017;14:331-7.

72. Pimpin L, Jebb S, Johnson L, Wardle J, Ambrosini GL. Dietary protein intake is associated with body mass index and weight up to $5 \mathrm{y}$ of age in a prospective cohort of twins. Am J Clin Nutr. 2016;103:389-97.

73. Gunther AL, Remer T, Kroke A, Buyken AE. Early protein intake and later obesity risk: which protein sources at which time points throughout infancy and childhood are important for body mass index and body fat percentage at $7 \mathrm{y}$ of age? Am J Clin Nutr. 2007;86:2-9.

74. Voortman T, Braun KVE, Kiefte-de JongJC, Jaddoe VWV, Franco $\mathrm{OH}$, van den Hooven EH. Protein intake in early childhood and body composition at the age of 6 years: the Generation R Study. Int J Obes. 2016;40:1018-25.

75. Trichopoulou A, Gnardellis C, Benetou V, Lagiou P, Bamia C, Trichopoulos D. Lipid, protein and carbohydrate intake in relation to body mass index. Eur J Clin Nutr. 2002;56:37-43.

76. Koletzko B, Von Kries R, Closa R, Escribano J, Scaglioni S, Giovannini M, et al. Lower protein in infant formula is associated with lower weight up to age $2 \mathrm{y}$ : a randomized clinical trial. Am J Clin Nutr. 2009;89:1836-45.

77. Solon-Biet SM, McMahon AC, Ballard JWO, Ruohonen K, $\mathrm{Wu}$ LE, Cogger VC, et al. The ratio of macronutrients, not caloric intake, dictates cardiometabolic health, aging, and longevity in ad libitum-fed mice. Cell Metab. 2014; 19:30.

78. Hörnell A, Lagström H, Lande B, Thorsdottir I. Protein intake from 0 to 18 years of age and its relation to health: a systematic literature review for the 5th Nordic Nutrition Recommendations. Food Nutr Res. 2013;57:21083.

79. Van Nielen M, Feskens EJM, Mensink M, Sluijs I, Molina E, Amiano P, et al. Dietary protein intake and incidence of type 2 diabetes in Europe: The EPIC-InterAct case-cohort study. Diabetes Care. 2014;37:1854-62.

80. Weber M, Grote V, Closa-Monasterolo R, Escribano J, Langhendries J-P, Dain E, et al. Lower protein content in infant formula reduces BMI and obesity risk at school age: follow-up of a randomized trial. Am J Clin Nutr. 2014;99:1041-51.

81. Patro-Gołąb B, Zalewski BM, Kołodziej M, Kouwenhoven S, Poston L, Godfrey KM, et al. Nutritional interventions or exposures in infants and children aged up to 3 years and their effects on subsequent risk of overweight, obesity and body fat: a systematic review of systematic reviews. Obes Rev. 2016;17:1245-57.

82. Newgard CB, An J, Bain JR, Muehlbauer MJ, Stevens RD, Lien $\mathrm{LF}$, et al. A branched-chain amino acid-related metabolic signature that differentiates obese and lean humans and contributes to insulin resistance. Cell Metab. 2009;9:311-26.

83. Lynch CJ, Adams SH. Branched-chain amino acids in metabolic signalling and insulin resistance. Nat Rev Endocrinol. 2014;10:723-36.

84. Fontana L, Cummings NE, Arriola SI, Alexander CM, Kimple ME, Lamming Correspondence DW, et al. Decreased consumption of branched-chain amino acids improves metabolic health. Cell Rep. 2016;16:520-30.

85. Levine ME, Suarez JA, Brandhorst S, Balasubramanian P, Cheng $\mathrm{CW}$, Madia F, et al. Low protein intake is associated with a major reduction in IGF-1, cancer, and overall mortality in the 65 and younger but not older population. Cell Metab. 2014;19:407-17.

86. Seidelmann SB, Claggett B, Cheng S, Henglin M, Shah A, Steffen LM et al. Dietary carbohydrate intake and mortality: a prospective cohort study and meta-analysis. Lancet Public Heal. 2018;3: E419-E428.

87. Reid M, Hammersley R. Sugars and obesity: meta-analysis establishes the strength of the correlation, not the cause. Nutr Bull. 2014;39:153-6.

88. Te Morenga L, Mallard S, Mann J. Dietary sugars and body weight: systematic review and meta-analyses of randomised controlled trials and cohort studies. BMJ. 2012;346:e7492.

89. Khan TA, Sievenpiper JL. Controversies about sugars: results from systematic reviews and meta-analyses on obesity, cardiometabolic disease and diabetes. Eur J Nutr. 2016;55:25-43.

90. Tappy L, Mittendorfer B. Fructose toxicity: is the science ready for public health actions? Curr Opin Clin Nutr Metab Care. 2012;15:357-61.

91. Lustig RH, Schmidt LA, Brindis CD. The toxic truth about sugar. Nature. 2012;482:27-29.

92. Egli L, Lecoultre V, Cros J, Rosset R, Marques AS, Schneiter P, et al. Exercise performed immediately after fructose ingestion enhances fructose oxidation and suppresses fructose storage. Am J Clin Nutr. 2016;103:348-55.

93. Bidwell AJ, Fairchild TJ, Redmond J, Wang L, Keslacy S, Kanaley JA. Physical activity offsets the negative effects of a high-fructose diet. Med Sci Sports Exerc. 2014;46:2091-8.

94. Tappy L, Rosset R. Fructose metabolism from a functional perspective: Implications for athletes. Sport Med. 2017;47:23-32.

95. Rowlands DS, Houltham S, Musa-Veloso K, Brown F, Paulionis L, Bailey D. Fructose-glucose composite carbohydrates and endurance performance: Critical review and future perspectives. Sport Med. 2015;45:1561-76.

96. Vergnaud A-C, Norat T, Mouw T, Romaguera D, May AM, Bueno-de-Mesquita HB, et al. Macronutrient composition of the diet and prospective weight change in participants of the EPICPANACEA study. PLoS ONE. 2013;8:e57300. 


\section{Affiliations}

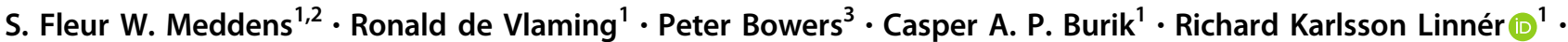
${\text { Chanwook } \text { Lee }^{3} \text { - Aysu Okbay } \mathbb{( D D}^{1} \cdot \text { Patrick Turley }}^{4,5,6}$ - Cornelius A. Rietveld $\mathbb{D}^{2,7,8}$ - Mark Alan Fontana ${ }^{9,10}$. Mohsen Ghanbari $\mathbb{D}^{7,11}$. Fumiaki Imamura $\mathbb{1}^{12} \cdot$ George McMahon ${ }^{13} \cdot$ Peter J. van der Most $\mathbb{D}^{14}$. Trudy Voortman $\mathbb{D}^{7} \cdot$ Kaitlin H. Wade $\mathbb{1}^{13} \cdot$ Emma L. Anderson ${ }^{13} \cdot$ Kim V. E. Braun $\mathbb{D}^{7} \cdot$ Pauline M. Emmett $^{15}$. Tonũ Esko ${ }^{16}$. Juan R. Gonzalez $\mathbb{D}^{17,18,19}$ • Jessica C. Kiefte-de Jong $\mathbb{D}^{7,20}$. Claudia Langenberg $\mathbb{( D}^{12}$. Jian'an Luan $\mathbb{D}^{12} \cdot$ Taulant Muka $^{7}$. Susan Ring $\mathbb{D}^{13} \cdot$ Fernando Rivadeneira $\mathbb{D}^{21} \cdot$ Harold Snieder $\mathbb{D}^{14}$. Frank J. A. van Rooij $\mathbb{1}^{7}$ • Bruce H. R. Wolffenbuttel $\left.\right|^{22} \cdot 23$ andMe Research Team - EPIC- InterAct Consortium • Lifelines Cohort Study $\cdot$ George Davey Smith $\mathbb{D}^{13} \cdot$ Oscar H. Franco ${ }^{7} \cdot$ Nita G. Forouhi $\mathbb{D}^{12} \cdot$ M. Arfan Ikram (D) ${ }^{7}$. Andre G. Uitterlinden $\mathbb{D}^{21}$ - Jana V. van Vliet-Ostaptchouk $\mathbb{D}^{22,23} \cdot$ Nick J. Wareham $^{12}$ - David Cesarini ${ }^{24}$. K. Paige Harden ${ }^{25} \cdot$ James J. Lee $\mathbb{C}^{26} \cdot$ Daniel J. Benjamin $\mathbb{E}^{6,27,28} \cdot$ Carson C. Chow ${ }^{29} \cdot$ Philipp D. Koellinger $^{1}$

1 Department of Economics, Vrije Universiteit Amsterdam, De Boelelaan 1105, 1081 HV Amsterdam, The Netherlands

2 Department of Applied Economics, Erasmus School of Economics, Erasmus University Rotterdam, Burgemeester, Oudlaan 50, 3062 PA Rotterdam, The Netherlands

3 Department of Economics, Harvard University, 1805 Cambridge St, Cambridge, MA 02138, USA

4 Analytical and Translational Genetics Unit, Massachusetts General Hospital, Richard B. Simches Research building, 185 Cambridge St, CPZN-6818, Boston, MA 02114, USA

5 Stanley Center for Psychiatric Genomics, The Broad Institute at Harvard and MIT, 75 Ames St, Cambridge, MA 02142, USA

6 Behavioral and Health Genomics Center, Center for Economic and Social Research, University of Southern, California, 635 Downey Way, Los Angeles, CA 90089, USA

7 Department of Epidemiology, Erasmus MC, University Medical Center, Wytemaweg 80, 3015 GE Rotterdam, The Netherlands

8 Erasmus University Rotterdam Institute for Behavior and Biology, Erasmus School of Economics, Erasmus, University Rotterdam, Burgemeester Oudlaan 50, 3062 PA Rotterdam, The Netherlands

9 Center for the Advancement of Value in Musculoskeletal Care, Hospital for Special Surgery, 535 East 70th Street, New York, NY 10021, USA

10 Department of Healthcare Policy and Research, Weill Cornell Medical College, Cornell University, 402 East 67th Street, New York, NY 10065, USA

11 Department of Genetics, School of Medicine, Mashhad University of Medical Sciences, Azadi Square, University Campus, 9177948564 Mashhad, Iran

12 MRC Epidemiology Unit, University of Cambridge School of Clinical Medicine, Institute of Metabolic Science, Cambridge Biomedical Campus Cambridge, CB2 0QQ Cambridge, UK

13 Integrative Epidemiology Unit, Population Health Sciences, Bristol Medical School, University of Bristol, Oakfield House, Oakfield Grove, BS8 2BN Bristol, UK

14 Department of Epidemiology, University of Groningen, University Medical Center Groningen, Hanzeplein 1, 9713 GZ Groningen, The Netherlands
15 Population Health Sciences, Bristol Medical School, University of Bristol, Oakfield House, Oakfield Grove, BS8, 2BN, Bristol, UK

16 Estonian Genome Center, University of Tartu, Riia 23b, Tartu 51010, Estonia

17 Barcelona Institute for Global Health (ISGlobal), Doctor Aiguader, 88, Barcelona 8003, Spain

18 Universitat Pompeu Fabra (UPF), Ramon Trias Fargas 25-27, Barcelona 8005, Spain

19 CIBER Epidemiología y Salud Pública (CIBERESP), Pabellón 11, Calle Monforte de Lemos, 3-5, Madrid 280229, Spain

20 Leiden University College, Anna van Buerenplein 301, 2595 DG Den Haag, The Netherlands

21 Department of Internal Medicine, Erasmus MC University Medical Center, Wytemaweg 80, 3015 GE Rotterdam, The Netherlands

22 Department of Endocrinology, University of Groningen, University Medical Center Groningen, Hanzeplein 1, 9713 GZ Groningen, The Netherlands

23 Genomics Coordination Center, Department of Genetics, University of Groningen, University Medical Center, Groningen, Hanzeplein 1, 9713 GZ Groningen, The Netherlands

24 Department of Economics, New York University, 19 W. 4th Street, New York, NY 10012, USA

25 Department of Psychology, University of Texas at Austin, 108 E. Dean Keeton Stop \#A8000, Austin, TX 78704, USA

26 Department of Psychology, University of Minnesota Twin Cities, 75 East River Parkway, Minneapolis, MN 55455, USA

27 National Bureau of Economic Research, 1050 Massachusetts Ave, Cambridge, MA 02138, USA

28 Department of Economics, University of Southern California, 635 Downey Way, Los Angeles, CA 90089, USA

29 Laboratory of Biological Modeling, National Institute of Diabetes and Digestive and Kidney Diseases, National, Institutes of Health, Bethesda, MD 20892, USA 